\title{
Height alone, rather than body surface area, suffices for risk estimation in ascending aortic aneurysm
}

\author{
Mohammad A. Zafar, MBBS, ${ }^{a}$ Yupeng Li, PhD, ${ }^{b}$ John A. Rizzo, PhD, ${ }^{\mathrm{c}}$ Paris Charilaou, MD, ${ }^{\mathrm{a}}$ \\ Ayman Saeyeldin, MD, ${ }^{a}$ Camilo A. Velasquez, MD, ${ }^{a}$ Ahmed M. Mansour, BA, ${ }^{a}$ \\ Syed Usman Bin Mahmood, MBBS, ${ }^{a}$ Wei-Guo Ma, MD, PhD, , , ${ }^{\text {d }}$ Adam J. Brownstein, BA, ${ }^{a}$ \\ Maryann Tranquilli, RN, ${ }^{\mathrm{a}}$ Julia Dumfarth, MD, ${ }^{\mathrm{a}}$ Panagiotis Theodoropoulos, MD, ${ }^{\mathrm{a}}$ Kabir Thombre, BA, ${ }^{\mathrm{a}}$ \\ Maryam Tanweer, MBBS, ${ }^{a}$ Young Erben, MD, ${ }^{\mathrm{e}}$ Sven Peterss, MD, ${ }^{\mathrm{f}}$ Bulat A. Ziganshin, MD, PhD, ${ }^{\mathrm{a}, \mathrm{g}}$ and \\ John A. Elefteriades, MD
}

\begin{abstract}
Background: In international guidelines, risk estimation for thoracic ascending aortic aneurysm (TAAA) is based on aortic diameter. We previously introduced the aortic size index (ASI), defined as aortic size/body surface area (BSA), as a predictor of aortic dissection, rupture, and death. However, weight might not contribute substantially to aortic size and growth. We seek to evaluate the height-based aortic height index (AHI) versus ASI for risk estimation and revisit our natural history calculations.
\end{abstract}

Methods: Aortic diameters and long-term complications of 780 patients with TAAA were analyzed. Growth rate estimates, yearly complication rates, and survival were assessed. Risk stratification was performed using regression models. The predictive value of AHI and ASI was compared.

Results: Patients were stratified into 4 categories of yearly risk of complications based on their ASI and AHI. ASIs $\left(\mathrm{cm} / \mathrm{m}^{2}\right)$ of $\leq 2.05,2.08$ to $2.95,3.00$ to 3.95 and $\geq 4$, and AHIs $(\mathrm{cm} / \mathrm{m})$ of $\leq 2.43,2.44$ to $3.17,3.21$ to 4.06 , and $\geq 4.1$ were associated with a $4 \%, 7 \%, 12 \%$, and $18 \%$ average yearly risk of complications, respectively. Five-year complication-free survival was progressively worse with increasing ASI and AHI. Both ASI and AHI were shown to be significant predictors of complications $(P<.05)$. AHI categories 3.05 to $3.69,3.70$ to 4.34 , and $\geq 4.35 \mathrm{~cm} / \mathrm{m}$ were associated with a significantly increased risk of complications $(P<.05)$. The overall fit of the model using AHI was modestly superior according to the concordance statistic.

Conclusions: Compared with indices including weight, the simpler height-based ratio (excluding weight and BSA calculations) yields satisfactory results for evaluating the risk of natural complications in patients with TAAA. (J Thorac Cardiovasc Surg 2018;155:1938-50)

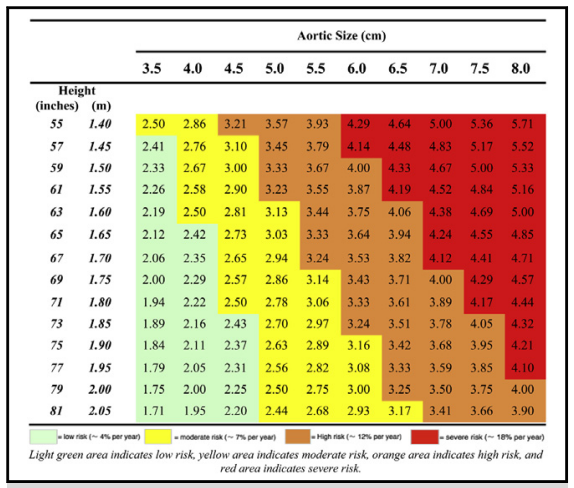

Risk of complications in ascending aortic aneurysm as a function of aortic diameter and height.

\section{Central Message}

In patients with ascending aortic aneurysm, a simple aortic diameter/height ratio showed very similar performance as diameter/BSA ratio in accurately predicting the risks of dissection, rupture, and death.

\section{Perspective}

Indexing absolute aortic diameter to anthropometric measurements provides individualized risk classification in patients with thoracic aortic aneurysm. Unlike weight, height does not change during adult life, and the AHI (aortic size/height) is as good as the ASI (aortic size/BSA) for risk stratification. Therefore, height-based relative aortic measures may be a more reliable long-term predictor of risk.

See Editorial Commentary page 1951.

See Editorial page 1925.
From the a Aortic Institute at Yale-New Haven Hospital, Yale University School of Medicine, New Haven, Conn; ${ }^{b}$ Department of Political Sciences and Economics,

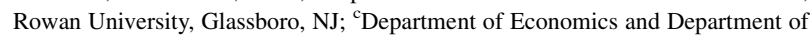
Preventive Medicine, Stony Brook University, Stony Brook, NY; ${ }^{\mathrm{d}}$ Department of Cardiovascular Surgery, Beijing Anzhen Hospital of Capital Medical University, Beijing, China; ${ }^{\mathrm{e}}$ Department of Vascular Surgery, Yale University School of Medicine, New Haven, Conn; ${ }^{\mathrm{f}}$ Department of Cardiac Surgery, University Hospital Munich, Ludwig Maximilian University, Munich, Germany; and ${ }^{\mathrm{g}}$ Department of Surgical Diseases 2, Kazan State Medical University, Kazan, Russia.

A.S., C.A.V., and A.M.M. contributed equally to this work.
Read at the 97th Annual Meeting of The American Association for Thoracic Surgery, Boston, Massachusetts, April 29-May 3, 2017.

Received for publication April 30, 2017; revisions received Aug 31, 2017; accepted for publication Oct 17, 2017; available ahead of print Feb 1, 2018.

Address for reprints: John A. Elefteriades, MD, Aortic Institute at Yale-New Haven, Yale University School of Medicine, Clinic Building CB 317789 Howard Ave, New Haven, CT 06519 (E-mail: john.elefteriades@yale.edu). $0022-5223 / \$ 36.00$

Copyright (C) 2017 by The American Association for Thoracic Surgery https://doi.org/10.1016/j.jtcvs.2017.10.140 

Abbreviations and Acronyms
AHI $=$ aortic height index
ASI $=$ aortic size index
BSA = body surface area
$\mathrm{CT}=$ computed tomography
MRI = magnetic resonance imaging
TAA $=$ thoracic aortic aneurysm
TAAA $=$ thoracic ascending aortic aneurysm
TEE = transesophageal echocardiography
TTE $=$ transthoracic echocardiography

Scanning this QR code will take you to a supplemental video. To view the AATS Annual Meeting Webcast, see the URL next to the webcast thumbnail.

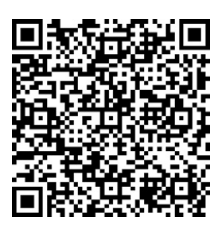

In international guidelines, preemptive surgical intervention criteria for thoracic ascending aortic aneurysm (TAAA) are based on absolute raw aortic diameter: $\geq 5.5 \mathrm{~cm}$ for asymptomatic TAAA and between 4.0 and $5.0 \mathrm{~cm}$ for various genetically effectuated aortopathies. ${ }^{1,2}$ These size cutoffs in turn are based on the established, escalating yearly and cumulative natural risk of devastating complicationsaortic rupture, dissection and/or death-with increasing degrees of aneurysmal aortic enlargement. ${ }^{1,3-5}$

A drawback of using aortic diameter in this regard for risk estimation is the inability to factor in a significant determinant of aortic dimensions: the patient's body size. ${ }^{6}$ To this end, in previous work, our group introduced and validated a relative aortic measure, the aortic size index (ASI), defined as aortic diameter divided by body surface area (BSA), as a more patient-specific predictor of dissection, rupture, and death than absolute aortic diameter. ${ }^{7}$

However, we came to suspect that a patient's weight might not contribute substantially to aortic size and growth. Moreover, weight fluctuates throughout the lifespan and can be deliberately influenced. Furthermore, indexing patient height to aortic dimensions has recently been shown to enhance mortality prognostication in patients with TAAA. ${ }^{8}$ Therefore, in the present study we compared the predictive value of a simple height-based relative aortic size measure, the aortic height index (AHI), defined as aortic size divided by patient height, with that of the BSA-corrected ASI for risk estimation of TAAA complications. We also revisit our previous calculations regarding the natural history of TAAA, using a significantly larger cohort of patients with ascending aortic aneurysm.

\section{METHODS}

This investigation was approved by the Human Investigation Committee of the Yale University School of Medicine.

\section{Patients}

As part of our ongoing investigations into the natural history of thoracic aortic aneurysm (TAA), our database at the Aortic Institute at Yale-New Haven Hospital currently includes a total of 3349 patients with TAA. Among these, 780 patients with a TAAA, with a total of 1272 ascending aortic size measurements and a mean radiologic follow-up of 47.7 months (range, 5 days to 256.7 months), compose a subset in which all radiologic studies were reread and reanalyzed in a standardized manner ${ }^{9}$ for the purpose of this study. Anthropometric, radiologic, and clinical data were manually accrued retrospectively from individual electronic medical records and hospital charts. All 780 patients had height and weight data available, a maximal ascending aortic size $\geq 3.5 \mathrm{~cm}$, and at least one verified aortic size measurement. Long-term survival follow-up was performed according to the Yale Aortic Institute method as described previously. ${ }^{10}$ Exclusion criteria included chronic Stanford type A and type B dissection

TABLE 1. Patient characteristics

\begin{tabular}{|c|c|}
\hline Variable & Value \\
\hline Total number of patients & 780 \\
\hline Males, n (\%) & $530(67.9)$ \\
\hline Females, n (\%) & $250(32.1)$ \\
\hline Age, $y$, mean \pm SD (range) & $61.9 \pm 15.0(14-94)$ \\
\hline Height, $\mathrm{cm}$, mean $\pm \mathrm{SD}$ (range) & $173.8 \pm 11.4(127-206)$ \\
\hline Weight, $\mathrm{kg}$, mean $\pm \mathrm{SD}$ (range) & $87.5 \pm 17.7(41-267)$ \\
\hline $\begin{array}{l}\text { Body surface area, } \mathrm{m}^{2}, \text { mean } \pm \mathrm{SD} \\
\quad \text { (range) }\end{array}$ & $1.99 \pm 0.27(1.273-3.399)$ \\
\hline $\begin{array}{l}\text { Aortic size index, } \mathrm{cm} / \mathrm{m}^{2} \text {, mean } \pm \mathrm{SD} \\
\quad \text { (range) }\end{array}$ & $2.507 \pm 0.578(1.354-6.624)$ \\
\hline $\begin{array}{l}\text { Aortic height index, } \mathrm{cm} / \mathrm{m}, \\
\text { mean } \pm \mathrm{SD} \text { (range) }\end{array}$ & $2.831 \pm 0.535(1.862-6.774)$ \\
\hline Bicuspid aortic valve, $\mathrm{n}(\%)$ & $197(25.2)$ \\
\hline Bovine aortic arch, $\mathrm{n}(\%)$ & $115(14.7)$ \\
\hline Marfan syndrome, n (\%) & $31(4.0)$ \\
\hline \multicolumn{2}{|l|}{ Family history, n (\%) } \\
\hline Proven & $174(22.3)$ \\
\hline Likely & $55(7.1)$ \\
\hline Possible & $41(5.3)$ \\
\hline Unknown & $106(13.6)$ \\
\hline None & $404(51.8)$ \\
\hline \multicolumn{2}{|l|}{ Previous cardiac surgeries, $\mathrm{n}(\%)$} \\
\hline AVR & $44(5.6)$ \\
\hline CABG & $23(2.9)$ \\
\hline MVR & $4(0.5)$ \\
\hline $\mathrm{AVR}+\mathrm{CABG}$ & $6(0.8)$ \\
\hline $\mathrm{AVR}+\mathrm{MVR}$ & $2(0.3)$ \\
\hline
\end{tabular}

$S D$, Standard deviation; $A V R$, aortic valve replacement; $C A B G$, coronary artery bypass grafting; $M V R$, mitral valve replacement. 
at presentation, congenital aortic malformations, and a history of traumatic aortic injury, thereby permitting an assessment of the natural history of TAAA. Other patient characteristics are listed in Table 1.

For the purpose of this study, the ascending aorta and arch (from the aortic annulus to the left subclavian artery) were considered one "unit," and the descending thoracic and thoracoabdominal portions (distal to the left subclavian artery) was considered a separate unit, reflecting the natural dichotomy of TAA disease above and below the ligamentum arteriosum (nonarteriosclerotic and arteriosclerotic, respectively). ${ }^{9}$ Thus, the maximal ascending or arch aortic diameter was considered the "ascending" size. In the great majority of patients, the largest diameter was found in the ascending portion of the aorta rather than in the arch. Aortic aneurysmectomy, acute flap-type aortic dissection, aortic rupture, and death were the study endpoints, at which we stopped tracking the natural history of the aortic segment afflicted.

Aortic valve morphology (bicuspid or trileaflet) was confirmed by direct visual inspection during aortic aneurysm surgery or by echocardiography in patients who did not undergo aneurysm surgery.

A patient was considered to have Marfan syndrome if confirmed by genetic testing or if manifesting classic clinical stigmata of the disease, as
To assess the rate of adverse events at different aortic sizes, both the ASI and AHI were stratified into 5 groups based on the distribution of the 2 indices as follows:

$$
\begin{aligned}
& \text { ASI }\left(\mathrm{cm} / \mathrm{m}^{2}\right):<2.00,2.00 \text { to } 2.74,2.75 \text { to } 3.49,3.50 \text { to } 4.24 \text {, and } \\
& \geq 4.25 \\
& \text { AHI }(\mathrm{cm} / \mathrm{m}):=2.40,2.40 \text { to } 3.04,3.05 \text { to } 3.69,3.70 \text { to } 4.34 \text {, and }
\end{aligned}
$$$$
\geq 4.35 \text {. }
$$

We tested for nonlinearities with respect to the AHI and ASI variables using spline regression and found no evidence of nonlinearities.

Multivariate analysis using a Cox proportional hazards model was performed to assess and identify the risk factors for major adverse events (death; dissection, or rupture and a composite endpoint including all 3). Kaplan-Meier and Cox proportional hazard models were used to estimate 5year event-free survival.

The average annual rate of adverse events (rupture, dissection, rupture or dissection, death (each alone separately), and a composite of rupture, dissection, and death) in 6 groups of aortic sizes was calculated by number of occurrences over the average duration of observations as follows:

\section{Total Number of Events

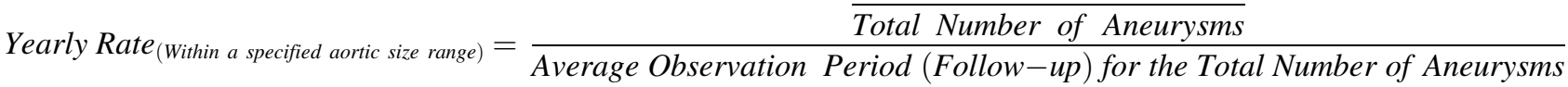

judged by the senior author (J.A.E). A patient was considered to have a positive family history of TAAA if a relative or relatives of the patient had a TAA or aortic dissection confirmed on an imaging study (computed tomography $[\mathrm{CT}]$, magnetic resonance imaging [MRI], transthoracic echocardiography [TTE], or transesophageal echocardiography [TEE]), intraoperatively, or on autopsy.

\section{Aortic Imaging}

All aortic diameter measurements were doubly confirmed by the senior author (J.A.E.) and by another senior team member (M.A.Z. or B.A.Z.). Official reports from the Department of Radiology at Yale-New Haven Hospital were also consulted. In the event of a discrepancy, data were reevaluated in a core meeting. Reports lacking accompanying images that could be measured were strictly excluded from the study.

CT, MRI, TEE, and TTE data were analyzed to determine aortic sizes. However, measurements from TEE and TTE were used only if they pertained to the proximal ascending aorta, because of the inability of these modalities to adequately visualize the upper portions of the ascending aorta. ${ }^{9}$ Serial measurements were performed at the identical level and plane in successive scans. Aortic rupture and acute flap-type aortic dissection were confirmed by CT/MRI, autopsy, or surgery.

We defined bovine aortic arch as the union of the innominate and left carotid arteries cranial to the plane of the greater curvature of the aortic arch. $^{11}$

\section{Statistical Methods}

Statistical analysis was performed using R 3.1.0 (R Foundation for Statistical Computing, Vienna, Austria). Data are expressed as mean \pm standard deviation and range for continuous variables and as number (percentage) for categorical variables.

BSA was computed using the Dubois and Dubois formula. ${ }^{12}$ ASI was defined as $A S I=\frac{\text { Aortic Diameter }(\mathrm{cm})}{B S A\left(\mathrm{~m}^{2}\right)}$, and AHI was defined as $A H I=\frac{\text { Aortic Diameter }(\mathrm{cm})}{\text { Height }(\mathrm{m})}$.
Growth rate estimates of the ascending aorta were obtained using an instrumental variables approach as previously described by our group. ${ }^{13,14}$ Patient age and sex, Marfan syndrome, family history, past cardiac surgery, bovine aortic arch configuration, and bicuspid aortic valve were included in the analysis to determine their effect on growth rate.

The predicted probability for risk of complication (rupture or dissection) was created from logistic regression. Aortic size, age, and sex were included in the analysis. For this risk of complication analysis, the aortic size groups were divided with 0.5-cm breakdown points (3.5-3.9, 4.0-4.4, 4.5-4.9, 5.0$5.4,5.5-5.9, \geq 6.0 \mathrm{~cm}$ ), and 4.0 to $4.4 \mathrm{~cm}$ was set as the comparison group.

\section{RESULTS}

\section{Aneurysm Size Distribution and Growth Rates}

The average maximal ascending aortic size before an endpoint or operative repair was $5.0 \pm 0.9 \mathrm{~cm}$ (range, 3.5$10.5 \mathrm{~cm}$ ). The overall distribution of aortic sizes of the patient cohort is depicted in Figure 1.

The estimated average yearly growth rate obtained by means of regression analysis was $0.14 \pm 0.02 \mathrm{~cm} /$ year: Larger aneurysms grew faster; a $3.5-\mathrm{cm}$ ascending aorta grew at $0.11 \mathrm{~cm} /$ year, whereas a $7.0-\mathrm{cm}$ aorta grew at $0.22 \mathrm{~cm} /$ year (Figure 2). Among the risk factors analyzed, only female sex (higher growth rate) and Marfan syndrome (higher growth rate) were predictive of aneurysm growth $(P<.05)$.

\section{Complication Rates and Event-Free Survival}

The average yearly rates of adverse events (rupture, dissection, and death) for 6 categories of ascending aortic sizes are presented in Figure 3, vividly demonstrating the importance of aortic size on complications rates. An aortic 


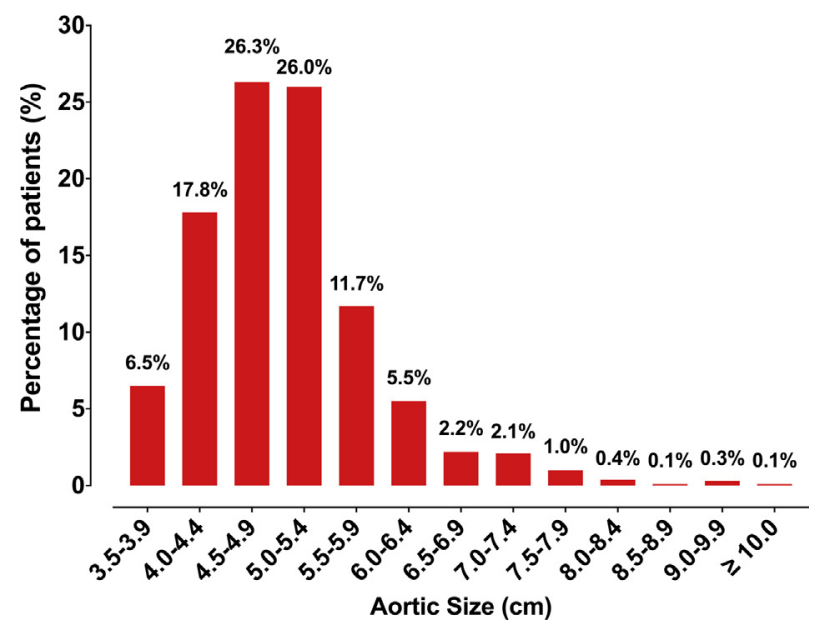

FIGURE 1. Distribution of maximal ascending aortic size of the patients before an endpoint or aortic surgery. The numbers on the histograms are the percentages of patients within that size range from among the entire cohort.

size of $>6.0 \mathrm{~cm}$ was associated with an almost 8 -fold higher average yearly rate of rupture, dissection, and death compared with an aortic size of 3.5 to $3.9 \mathrm{~cm}$ (Figure 3, B).

An analysis of the estimated probability of risk of rupture and dissection at various aortic sizes revealed that the risk increased sharply between 5.25 and $5.5 \mathrm{~cm}$ and then again between 5.75 and $6 \mathrm{~cm}$ (Figure 4). This figure also depicts the probability of rupture or acute dissection by initial aneurysm size. An aortic size of $\geq 6.0 \mathrm{~cm}$ was associated with an 8-percentage point increase in the probability of rupture and dissection relative to the 4.0 to $4.4 \mathrm{~cm}$ reference group $(P<.05)$. Multivariable regression analysis revealed that the odds of sustaining rupture or dissection were 2.6-fold greater in patients with aneurysms $\geq 6.0 \mathrm{~cm}$ compared with patients with aneurysms in the 4.0 to $4.4 \mathrm{~cm}$ range $(P<.05)$ (Table 2$)$.

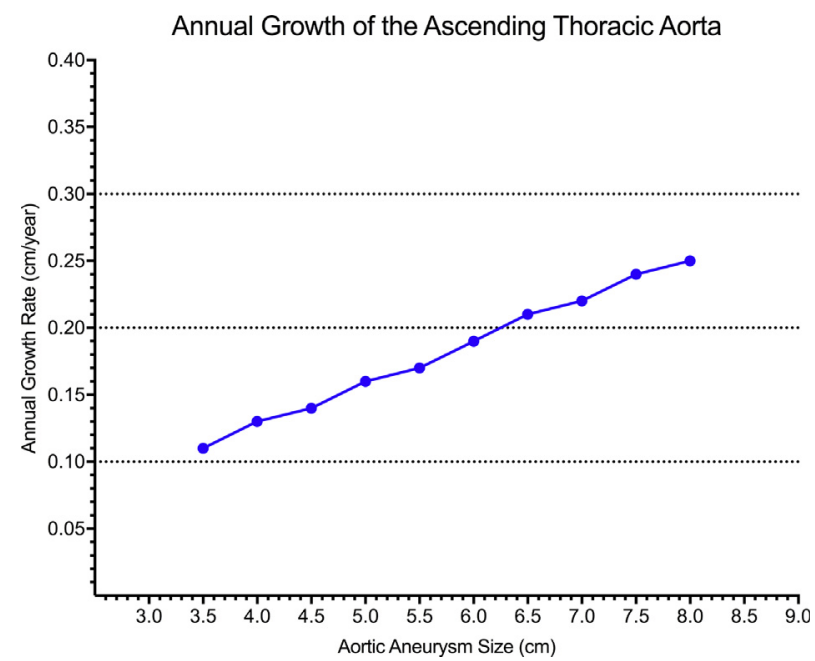

FIGURE 2. Average annual growth rate of the ascending aorta based on initial aneurysm size.

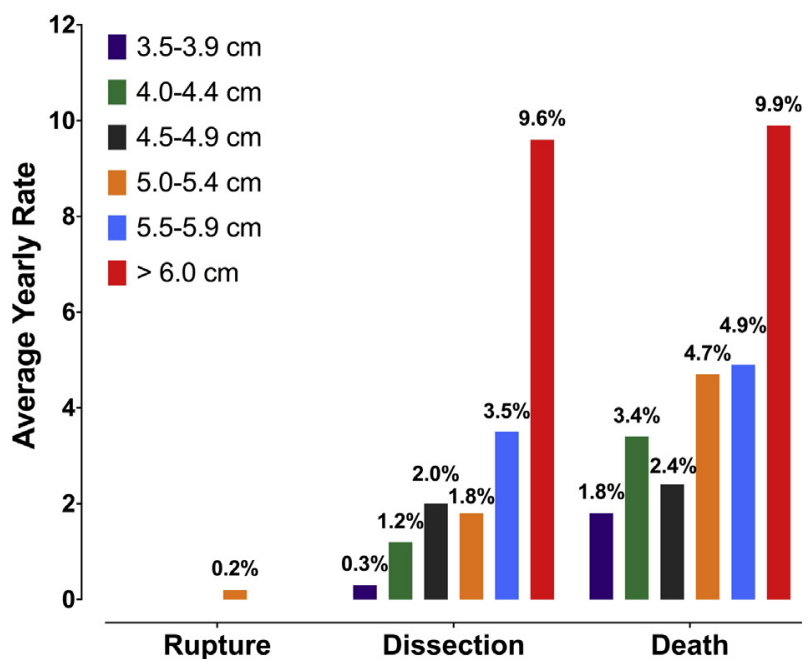

A

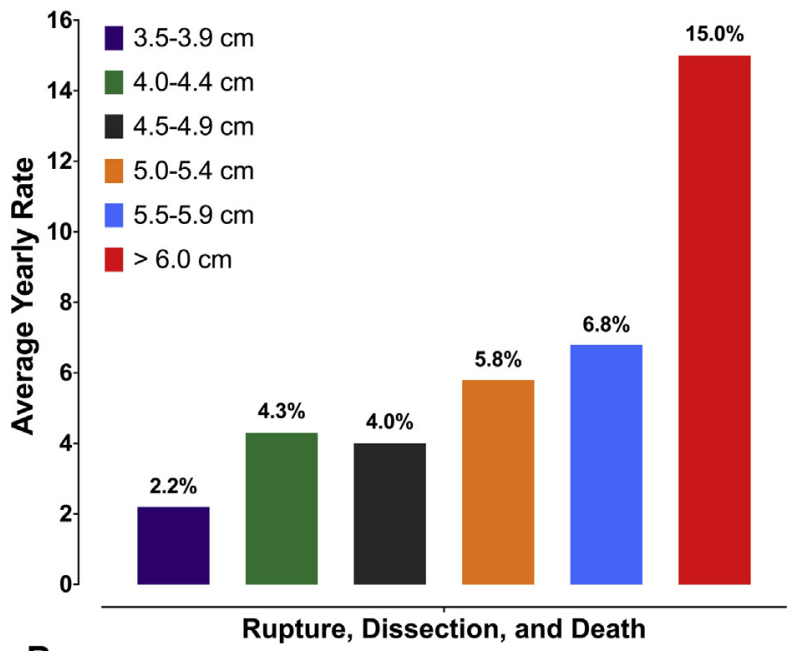

B

FIGURE 3. Yearly rates of adverse events related to ascending aortic aneurysm size. A, Yearly rates of rupture, dissection and death at various aortic sizes. B, Average yearly rates of the composite endpoint of rupture, dissection and death at various aortic sizes.

The 5-year complication-free survival is illustrated for ascending aortic aneurysm patients as a function of AHI and ASI in Figures 5, $A-C$, and 6, $A-C$, respectively. Higher AHI and ASI values were both associated with decreased survival in all 3 categories.

The 5-year survival functions estimated using Cox proportional hazards regression and stratified by ASI and AHI are shown in Figures 7, $A-C$ and $8, A-C$, respectively. The predicted 5-year rupture, dissection, and death-free survival in patients with TAAA is $85.5 \%$ in those with an ASI $<2.00 \mathrm{~cm} / \mathrm{m}^{2}$ and $86.6 \%$ in those with an AHI $<2.4 \mathrm{~cm} / \mathrm{m}$, versus $4.9 \%$ in those with an ASI $\geq 4.25 \mathrm{~cm} / \mathrm{m}^{2}$ and $9.5 \%$ in those with an $\mathrm{AHI} \geq 4.35 \mathrm{~cm} / \mathrm{m}$.

Cox proportional hazard regression analysis (Table 3 ) revealed a 6 -fold increased hazard function for the combined 


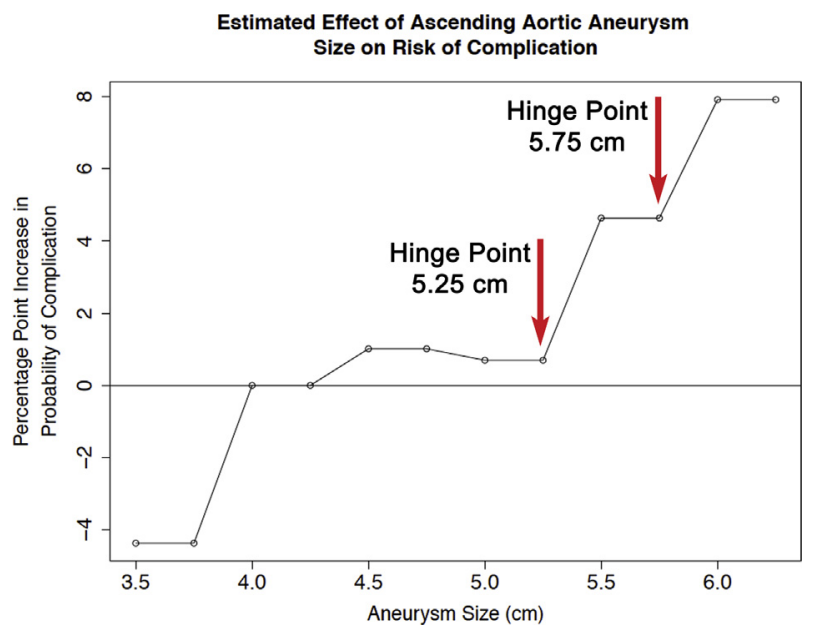

FIGURE 4. Estimated probability of rupture or dissection of the ascending aorta by aneurysm size.

endpoint of rupture, dissection, and death in patients with an ASI $\geq 4.25 \mathrm{~cm} / \mathrm{m}^{2}\left(P=2.53 \times 10^{-5}\right)$ compared with those with an ASI of 2.00 to $2.74 \mathrm{~cm} / \mathrm{m}^{2}$. For patients with an AHI $\geq 4.35 \mathrm{~cm} / \mathrm{m}$, the hazard function was $>5.5$-fold higher compared with those with an AHI of 2.40 to $3.04 \mathrm{~cm} / \mathrm{m}$ $\left(P=3.09 \times 10^{-6}\right)$. Older age was associated with an increased hazard, but sex was uncorrelated with the endpoints.

\section{Risk Stratification}

Patients were stratified into 4 categories of yearly risk of complications (rupture, dissection, and death) based on their ASI and AHI (Figures 9 and 10, respectively). ASIs of $\leq 2.05,2.08$ to $2.95,3.00$ to 3.95 , and $\geq 4 \mathrm{~cm} / \mathrm{m}^{2}$ were associated with an average annual risk of complications of $4 \%, 7 \%, 12 \%$ and $18 \%$ respectively. Comparably, AHIs of $\leq 2.43,2.44$ to $3.17,3.21$ to 4.06 , and $\geq 4.1 \mathrm{~cm} /$ $\mathrm{m}$ were associated with an average annual risk of complications of $4 \%, 7 \%, 12 \%$, and $18 \%$, respectively.

When evaluated by the new AHI risk estimation index, 173 patients $(22.2 \%)$ changed risk category; 95 (12.2\%) went up a category, and $78(10 \%)$ went down a category.

TABLE 2. Logistic regression analysis of factors predicting the composite endpoint of rupture and dissection, based on aortic size

\begin{tabular}{lcccc}
\hline \multicolumn{1}{c}{ Variable } & $\begin{array}{c}\text { Parameter } \\
\text { estimate }\end{array}$ & $\begin{array}{c}\text { Odds } \\
\text { ratio }\end{array}$ & $\begin{array}{c}\text { Standard } \\
\text { error }\end{array}$ & $\boldsymbol{P}$ value \\
\hline Aortic size, cm & & & & \\
$\quad$ Intercept term & -2.162 & 0.115 & 0.715 & .003 \\
$3.5-3.9$ & -1.589 & 0.204 & 1.066 & .136 \\
$4.5-4.9$ & 0.1785 & 1.195 & 0.443 & .687 \\
$5.0-5.4$ & 0.125 & 1.134 & 0.465 & .787 \\
$5.5-5.9$ & 0.657 & 1.929 & 0.512 & .199 \\
$\geq 6$ & 0.973 & 2.647 & 0.486 & .045 \\
Male sex & -0.093 & 0.911 & 0.322 & .774 \\
Age & -0.010 & 0.990 & 0.010 & .302 \\
\hline
\end{tabular}

\section{ASI Versus AHI as a Predictor of Complications}

The coefficient estimates for both ASI and AHI demonstrate a statistically significant effect on the complication rate ( $P$ values listed in Table 3$)$. According to the concordance measures $(0.617$ for the model using ASI and 0.645 for the model using AHI), AHI performs not only as well, but actually slightly better than ASI in predicting rupture, dissection, and death. An area under the curve analysis provides a visual depiction of the slight superiority of AHI in predicting complications (Figure 11). ${ }^{15-17}$

\section{Analyses Excluding Patients With Marfan Syndrome and Bicuspid Aortic Valve}

In light of the fact that TAAA arising in patients with Marfan syndrome and bicuspid aortic valve are distinct, genetically effectuated aortopathies, we repeated the analyses in a cohort devoid of these 2 patient groups, and obtained similar results.

\section{DISCUSSION}

Two decades have elapsed since our original articles regarding the natural history of TAA, based on 230 patients with ascending and descending thoracic aortic aneurysms, were published. ${ }^{4,5,18,19}$ In the present study, we report natural history data from a group of 780 patients exclusively with TAAA. Consonant with our previous findings, we found that the ascending thoracic aorta grows slowly, at a rate of $0.14 \mathrm{~cm} /$ year. This demonstrates again that although a virulent disease, TAAA is an indolent process.

Aortic size remains an important surgical intervention criterion and an accurate predictor of the natural risks of TAA. Figure 3, $B$, shows the dominating effect of increasing aortic size, especially $>6 \mathrm{~cm}$, on annual complication rates. Compared with previous iterations of this analysis, ${ }^{9}$ it seems as if our aggressive approach to thoracic aortic disease in our environment has been impacting the natural history of TAAA. Dissection and rupture are no longer the primary contributors to complications; rather, death in patients not previously known to us is becoming the main contributor. Therefore, the focus and challenge for the future will be to identify those asymptomatic individuals who die from this disease before being diagnosed. ${ }^{20}$ It seems that once we detect an aneurysm, we can keep the patient safe through monitoring and size-triggered preventive surgery.

Figure 4 depicts the estimated probability of risk of natural complications (rupture and dissection) and 2 "hinge points" at the aortic sizes associated with increased risk of rupture and dissection. One sharp hinge point is observed at 5.75 to $6 \mathrm{~cm}$, as reported previously by our group. ${ }^{4}$ Interestingly, a second hinge point is also seen at 5.25 to $5.5 \mathrm{~cm}$. The much larger number of patients included in the present study allowed us to subcategorize size into tighter intervals. This more accurate division of the size range above $5 \mathrm{~cm}$ 
Kaplan-Meier Curve for Death by $\mathrm{AHI}$

AHI - Below $2.40-2.40$ to $3.04-3.05$ to $3.69-3.70$ to $4.34=$ Above 4.35
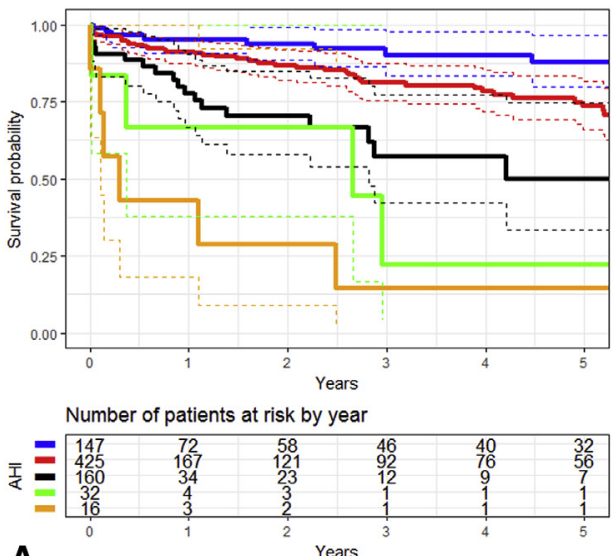

A

Kaplan-Meier Curve for

Rupture and Dissection by $\mathrm{AH}$

$\mathrm{AHI}-$ Below $2.40-2.40$ to $3.04-3.05$ to $3.69-3.70$ to 4.34 - Above 4.35

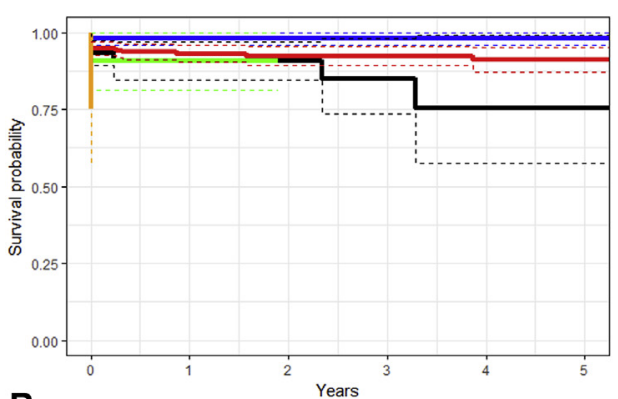

B Number of patients at risk by year

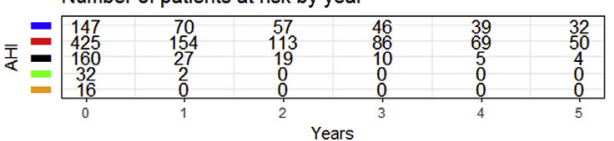

Kaplan-Meier Curve for

Rupture Dissection and Death by $\mathrm{AH}$

AHI - Below $2.40-2.40$ to $3.04-3.05$ to $3.69=3.70$ to $4.34=$ Above 4.35
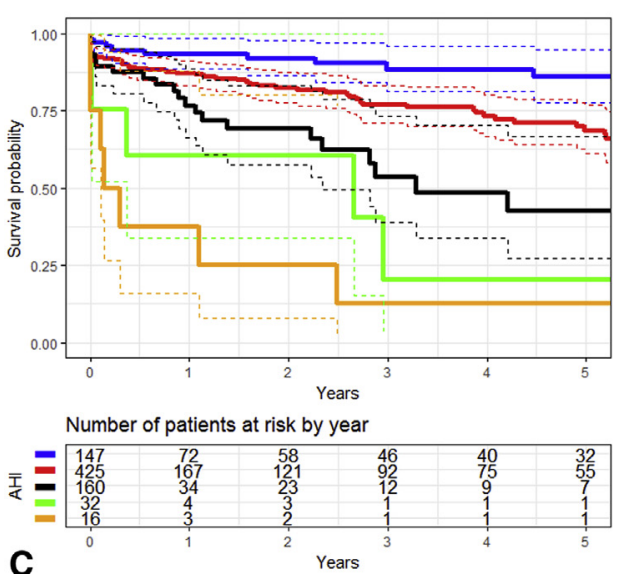

FIGURE 5. Kaplan-Meier estimates of freedom from death (A), rupture or dissection (B), and rupture, dissection, or death (C) as stratified by aortic height index $(A H I)$.

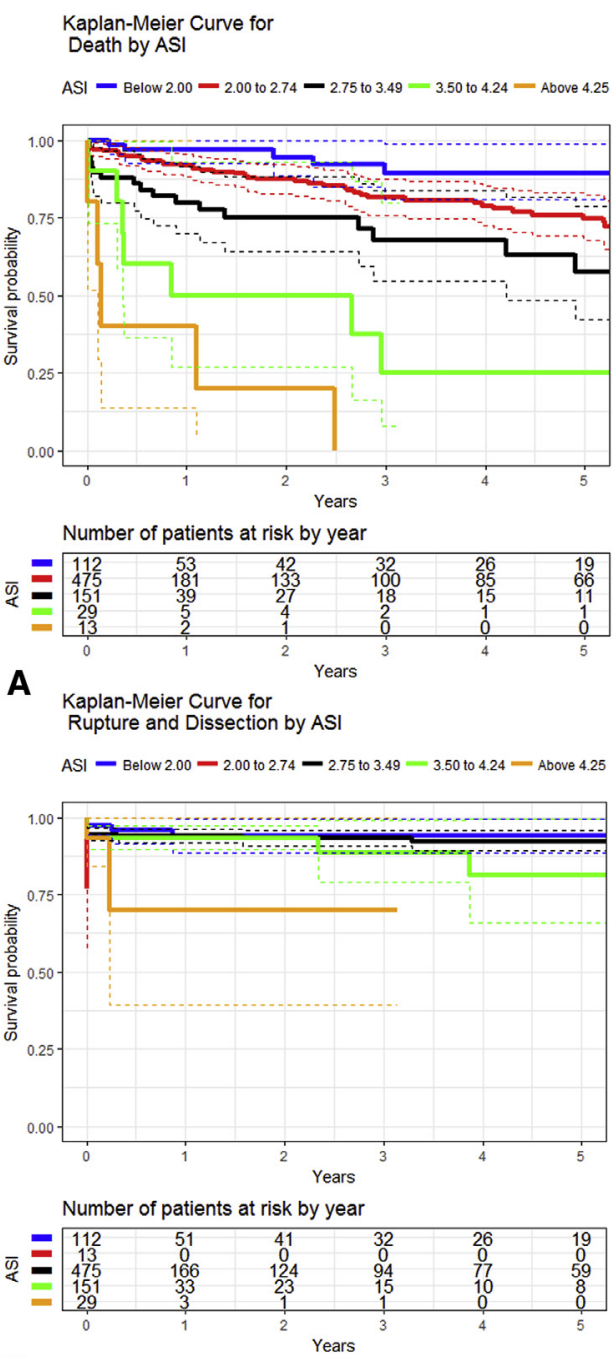

B Kaplan-Meier Curve for

Rupture,Dissection and Death by AS

ASI - Below $2.00-2.00$ to $2.74-2.75$ to $3.49=3.50$ to $4.24-$ Above 4.25
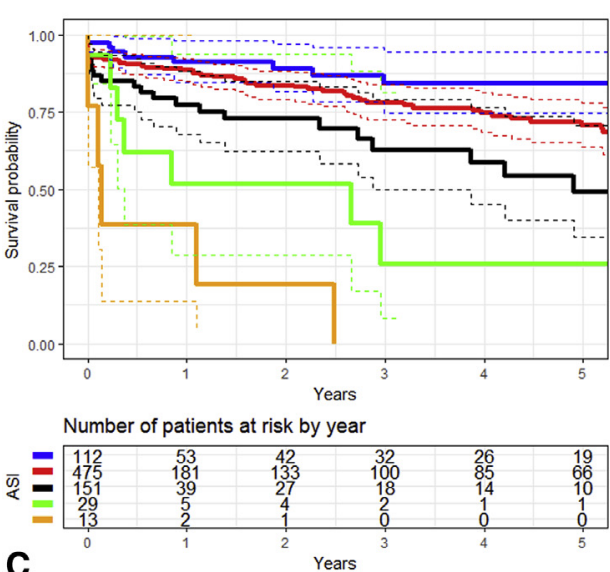

FIGURE 6. Kaplan-Meier estimates of freedom from death (A), rupture or dissection (B), and rupture, dissection, or death (C) as stratified by aortic size index $(A S I)$ 


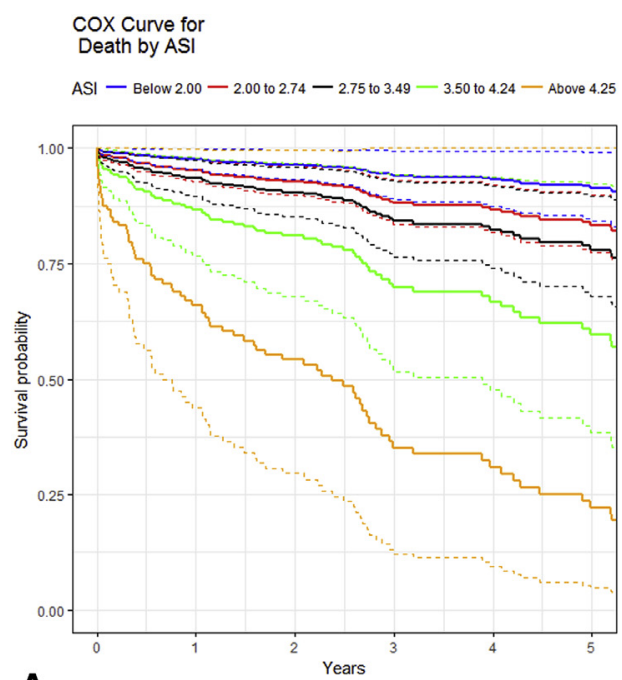

A Cox Curve for Rupture and Dissection by ASI

ASI - Below $2.00-2.00$ to $2.74-2.75$ to $3.49-3.50$ to 4.24 - Above 4.25

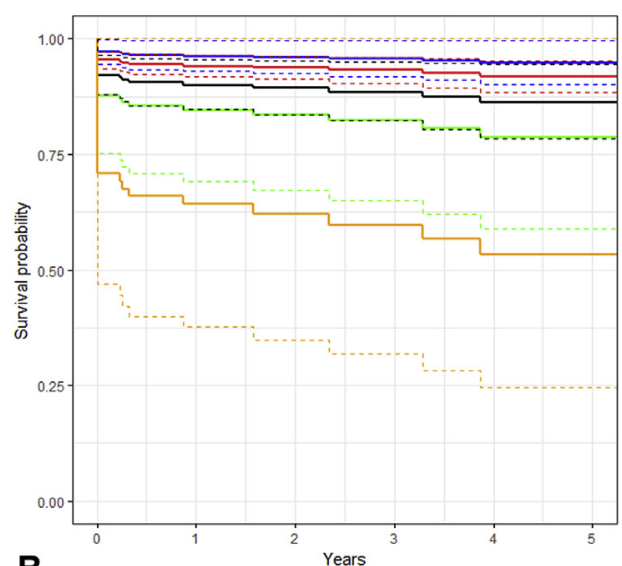

B Cox Curve for Rupture, Dissection and Death by ASI

ASI - Below $2.00-2.00$ to $2.74-2.75$ to $3.49-3.50$ to 4.24 - Above 4.25

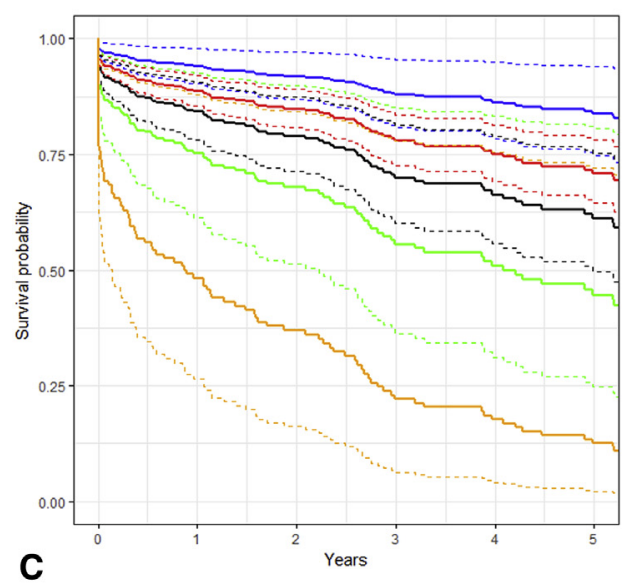

FIGURE 7. Cox proportional hazards regression for freedom from death (A), rupture or dissection (B), and rupture, dissection, or death (C) as stratified by aortic size index (ASI).

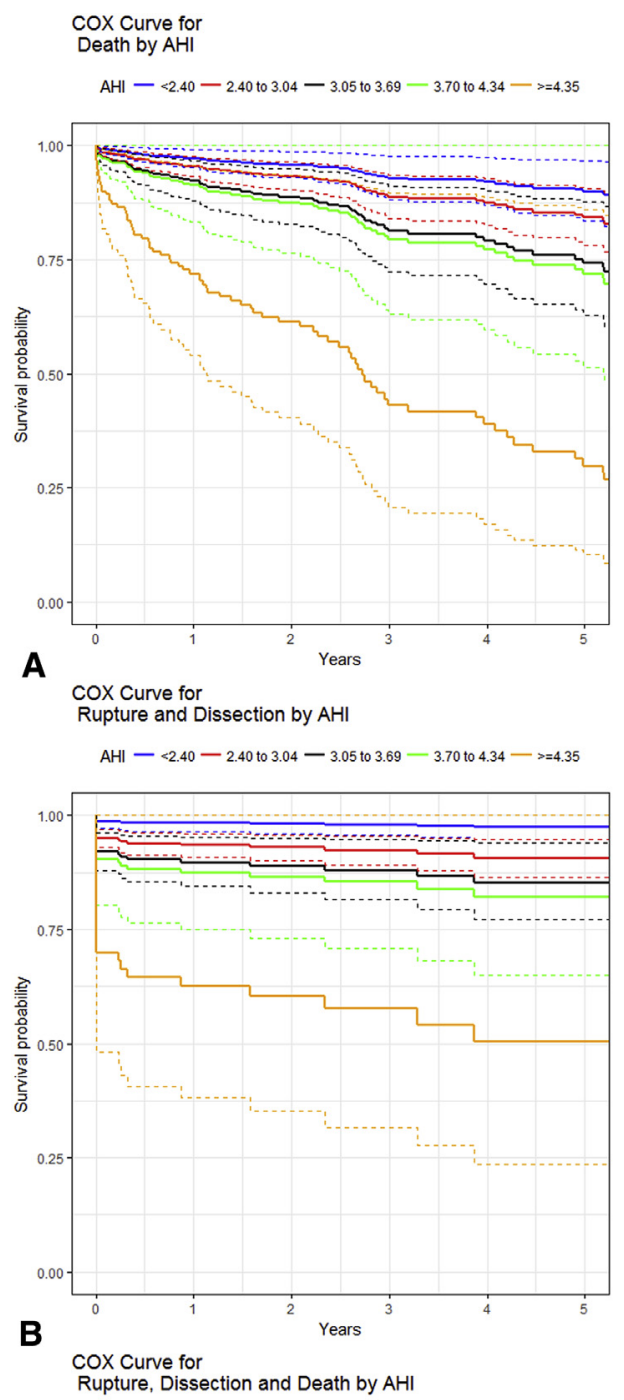

$\mathrm{AHI}-<2.40-2.40$ to $3.04-3.05$ to $3.69-3.70$ to $4.34->=4.35$

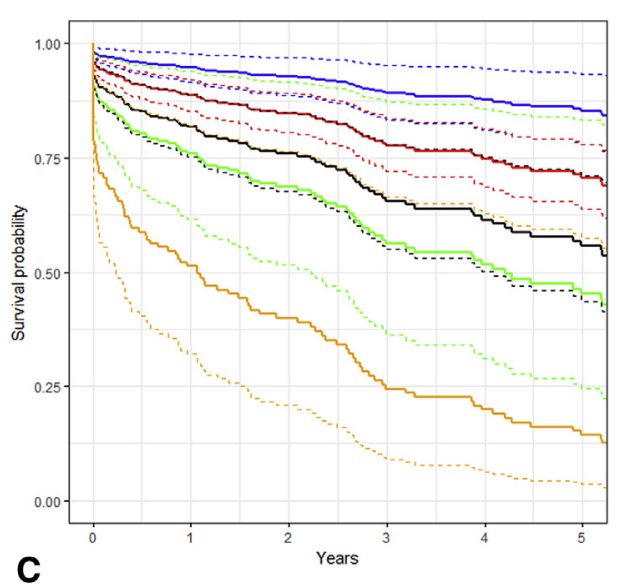

FIGURE 8. Cox proportional hazards regression for freedom from death (A), rupture or dissection (B), and rupture, dissection, or death (C) as stratified by aortic height index $(A H I)$. 
TABLE 3. Factors predicting the composite endpoint of rupture, dissection, and death based on aortic size index and aortic height index

\begin{tabular}{|c|c|c|c|c|c|}
\hline Variable & Coefficient & Hazard ratio & Standard error & $z$ & $P$ value \\
\hline \multicolumn{6}{|c|}{ Aortic size index, $\mathrm{cm} / \mathrm{m}^{2} *$} \\
\hline$<2.00$ & -0.667 & 0.513 & 0.340 & -1.96 & .050 \\
\hline $2.75-3.49$ & 0.356 & 1.428 & 0.223 & 1.601 & .109 \\
\hline $3.50-4.24$ & 0.852 & 2.345 & 0.372 & 2.29 & .022 \\
\hline$\geq 4.25$ & 1.796 & 6.023 & 0.426 & 4.212 & $2.53 \times 10^{-5}$ \\
\hline Age & 0.038 & 1.039 & 0.007 & 5.034 & $4.79 \times 10^{-7}$ \\
\hline Male sex & 0.188 & 1.207 & 0.196 & 0.959 & .337 \\
\hline \multicolumn{6}{|c|}{ Aortic height index, $\mathrm{cm} / \mathrm{m} \dagger$} \\
\hline$<2.40$ & -0.783 & 0.457 & 0.306 & -2.555 & .011 \\
\hline $3.05-3.69$ & 0.516 & 1.675 & 0.220 & 2.348 & .019 \\
\hline $3.70-4.34$ & 0.823 & 2.277 & 0.391 & 2.104 & .035 \\
\hline$\geq 4.35$ & 1.716 & 5.564 & 0.368 & 4.665 & $3.09 \times 10^{-6}$ \\
\hline Age & 0.037 & 1.038 & 0.007 & 4.943 & $7.69 \times 10^{-7}$ \\
\hline Male sex & 0.166 & 1.180 & 0.196 & 0.845 & .398 \\
\hline
\end{tabular}

Note the extremely powerful $P$ values for the higher aortic size index and aortic height index, which we have expressed exponentially. $*$ Concordance $=0.617$. $\dagger$ Concordance $=0.645$.

suggests that we may need to move the intervention criterion "leftward", toward a smaller size.

It is important to keep in mind that natural history studies on the aorta, and the calculations in this study, are based on observed size at the time of dissection. Recent evidence indicates that the aorta grows by $\sim 7$ to $8 \mathrm{~mm}$ at the instant of dissection. ${ }^{21-23}$ Thus, the aorta is actually quite a bit smaller just before the dissection. This emerging understanding will

Aortic Size (cm)

\begin{tabular}{|c|c|c|c|c|c|c|c|c|c|c|}
\hline & 3.5 & 4.0 & 4.5 & 5.0 & 5.5 & 6.0 & 6.5 & 7.0 & 7.5 & 8.0 \\
\hline \multicolumn{11}{|l|}{$\begin{array}{l}\text { BSA } \\
\left(\mathrm{m}^{2}\right)\end{array}$} \\
\hline 1.30 & 2.69 & 3.08 & 3.46 & 3.85 & 4.23 & 4.62 & 5.00 & 5.38 & 5.77 & 6.15 \\
\hline 1.40 & 2.50 & 2.86 & 3.21 & 3.57 & 3.93 & 4.29 & 4.64 & 5.00 & 5.36 & 5.71 \\
\hline 1.50 & 2.33 & 2.67 & 3.00 & 3.33 & 3.67 & 4.00 & 4.33 & 4.67 & 5.00 & 5.33 \\
\hline 1.60 & 2.19 & 2.50 & 2.80 & 3.13 & 3.44 & 3.75 & 4.06 & 4.38 & 4.69 & 5.00 \\
\hline 1.70 & 2.05 & 2.35 & 2.65 & 2.94 & 3.24 & 3.53 & 3.82 & 4.12 & 4.41 & 4.71 \\
\hline 1.80 & 1.94 & 2.22 & 2.50 & 2.78 & 3.06 & 3.33 & 3.61 & 3.89 & 4.17 & 4.44 \\
\hline 1.90 & 1.84 & 2.11 & 2.37 & 2.63 & 2.89 & 3.16 & 3.42 & 3.68 & 3.95 & 4.22 \\
\hline 2.00 & 1.75 & 2.00 & 2.25 & 2.50 & 2.75 & 3.00 & 3.25 & 3.50 & 3.75 & 4.00 \\
\hline 2.10 & 1.67 & 1.90 & 2.14 & 2.38 & 2.62 & 2.86 & 3.10 & 3.33 & 3.57 & 3.80 \\
\hline 2.20 & 1.59 & 1.82 & 2.05 & 2.27 & 2.50 & 2.72 & 2.95 & 3.18 & 3.41 & 3.64 \\
\hline 2.30 & 1.52 & 1.74 & 1.96 & 2.17 & 2.39 & 2.61 & 2.83 & 3.04 & 3.26 & 3.48 \\
\hline 2.40 & 1.46 & 1.67 & 1.88 & 2.08 & 2.29 & 2.50 & 2.71 & 2.92 & 3.13 & 3.33 \\
\hline 2.50 & 1.40 & 1.60 & 1.80 & 2.00 & 2.20 & 2.40 & 2.60 & 2.80 & 3.00 & 3.20 \\
\hline
\end{tabular}

FIGURE 9. Risk of complications (aortic dissection, rupture and death) in ascending aortic aneurysm patients as a function of aortic diameter (horizontal axis) and body surface area (vertical axis), with the aortic size index given within the figure. Light green indicates low risk; yellow, moderate risk; orange, high risk; red, severe risk. BSA, Body surface area. 


\begin{tabular}{|c|c|c|c|c|c|c|c|c|c|c|c|}
\hline & & \multicolumn{10}{|c|}{ Aortic Size (cm) } \\
\hline & & 3.5 & 4.0 & 4.5 & 5.0 & 5.5 & 6.0 & 6.5 & 7.0 & 7.5 & 8.0 \\
\hline \multicolumn{12}{|c|}{\begin{tabular}{l}
\multicolumn{2}{c}{ Height } \\
(inches) (m)
\end{tabular}} \\
\hline 55 & 1.40 & 2.50 & 2.86 & 3.21 & 3.57 & 3.93 & 4.29 & 4.64 & 5.00 & 5.36 & 5.71 \\
\hline 57 & 1.45 & 2.41 & 2.76 & 3.10 & 3.45 & 3.79 & 4.14 & 4.48 & 4.83 & 5.17 & 5.52 \\
\hline 59 & 1.50 & 2.33 & 2.67 & 3.00 & 3.33 & 3.67 & 4.00 & 4.33 & 4.67 & 5.00 & 5.33 \\
\hline 61 & 1.55 & 2.26 & 2.58 & 2.90 & 3.23 & 3.55 & 3.87 & 4.19 & 4.52 & 4.84 & 5.16 \\
\hline 63 & 1.60 & 2.19 & 2.50 & 2.81 & 3.13 & 3.44 & 3.75 & 4.06 & 4.38 & 4.69 & 5.00 \\
\hline 65 & 1.65 & 2.12 & 2.42 & 2.73 & 3.03 & 3.33 & 3.64 & 3.94 & 4.24 & 4.55 & 4.85 \\
\hline 67 & 1.70 & 2.06 & 2.35 & 2.65 & 2.94 & 3.24 & 3.53 & 3.82 & 4.12 & 4.41 & 4.71 \\
\hline 69 & 1.75 & 2.00 & 2.29 & 2.57 & 2.86 & 3.14 & 3.43 & 3.71 & 4.00 & 4.29 & 4.57 \\
\hline 71 & 1.80 & 1.94 & 2.22 & 2.50 & 2.78 & 3.06 & 3.33 & 3.61 & 3.89 & 4.17 & 4.44 \\
\hline 73 & 1.85 & 1.89 & 2.16 & 2.43 & 2.70 & 2.97 & 3.24 & 3.51 & 3.78 & 4.05 & 4.32 \\
\hline 75 & 1.90 & 1.84 & 2.11 & 2.37 & 2.63 & 2.89 & 3.16 & 3.42 & 3.68 & 3.95 & 4.21 \\
\hline 77 & 1.95 & 1.79 & 2.05 & 2.31 & 2.56 & 2.82 & 3.08 & 3.33 & 3.59 & 3.85 & 4.10 \\
\hline 79 & 2.00 & 1.75 & 2.00 & 2.25 & 2.50 & 2.75 & 3.00 & 3.25 & 3.50 & 3.75 & 4.00 \\
\hline 81 & 2.05 & 1.71 & 1.95 & 2.20 & 2.44 & 2.68 & 2.93 & 3.17 & 3.41 & 3.66 & 3.90 \\
\hline & 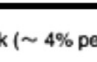 & & loderate & . & ar) & $=\mapsto$ & & & $=$ & & o pery \\
\hline
\end{tabular}

FIGURE 10. Risk of complications (aortic dissection, rupture, and death) in patients with ascending aortic aneurysm as a function of aortic diameter (horizontal axis) and height (vertical axis), with the aortic height index given within the figure. Light green indicates low risk; yellow, moderate risk; orange, high risk; red, severe risk.

likely lend further credence to a "left shift" of criteria for intervention. This critical topic is outside the immediate scope of this article, but is discussed in depth in a recent publication by our group. ${ }^{23}$

Based on the present study, we have been able to provide updated ASI (aortic size corrected to BSA) and AHI (aortic size corrected to height) nomograms for clinical decision making (Figures 9 and 10). These charts provide specific, detailed, and improved risk stratification information.

The concept of indexing aortic dimensions to patient stature to better inform surgical decision making in patient with aneurysms was proposed by Svensson and colleagues. ${ }^{24,25}$ In a previous study by our group, we introduced a novel relative aortic size measure, the ASI, which was found to have predictive value for dissection, rupture, and death in patients with TAAs. This predictive value of the ASI was again demonstrated in the present study, with a much larger group of patients with exclusively TAAAs. However, computing the BSA factors in patient weight, with is prone to significant fluctuation throughout adulthood. In contrast, height remains fairly constant and is not prone to wide fluctuations. The slightly lower concordance index for our model using the ASI compared with the model using the AHI (0.617 vs 0.645$)$ suggests that the ASI is "noisier" and a less reliable predictor of risk, an unsurprising finding given that weight affects the ASI and weight can fluctuate greatly over time. Furthermore, because height is genetically predetermined, it may be more closely correlated to aortic size.

Two patients with identical aortic size and height will have the same risk of complications using the AHI. But if one person is heavier than the other (and thus has a greater BSA), the ASI will assign the heavier individual a lower risk of adverse events. In this example, the ASI measure is a less accurate indicator of risk. Consequently, we considered that indexing aortic size to height alone might be a more precise and simpler risk assessment tool. Our findings in this study confirm that the height-based relative aortic measure, the 

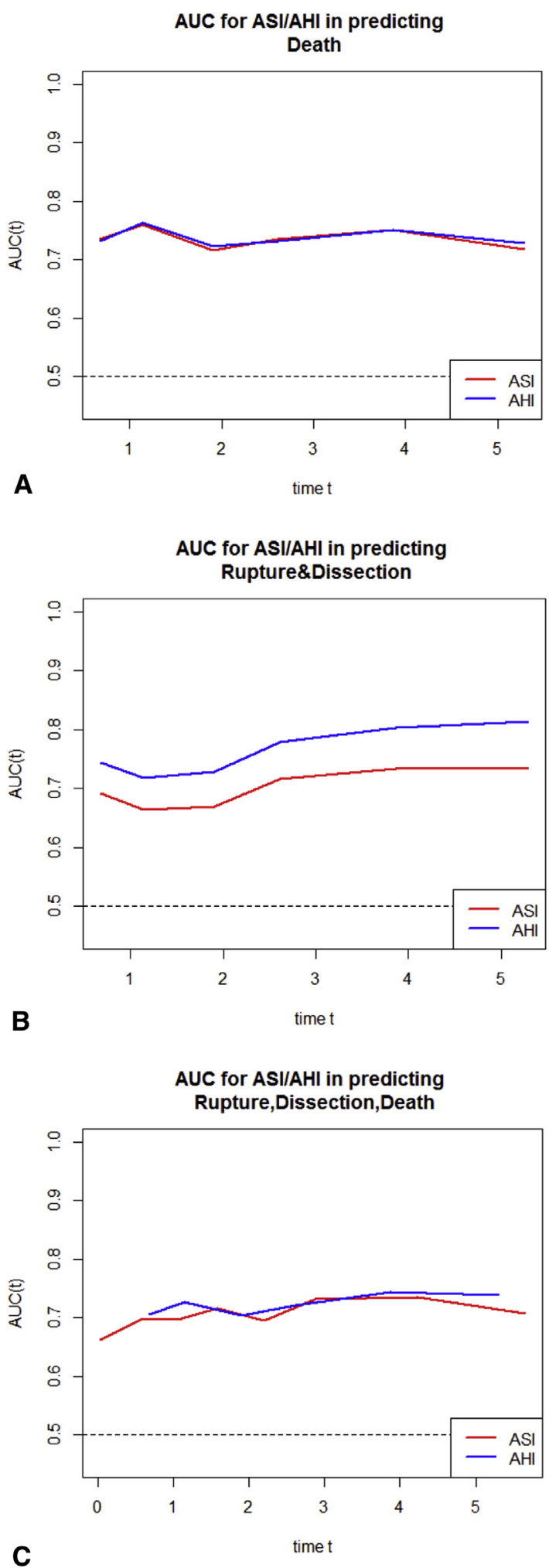

FIGURE 11. Area under curve analysis for aortic size index $(A S I) /$ aortic height index $(A H I)$ in predicting death (A), rupture and dissection (B), and rupture, dissection, and death $(C)$

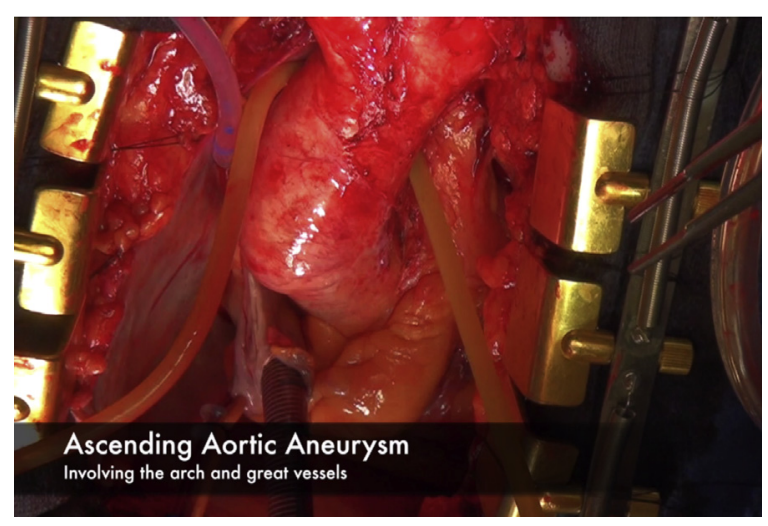

VIDEO 1. In 1997, our group first reported on the natural history of the thoracic aorta. We displayed "hinge points" at which aortic rupture or dissection occurred, without any correction for a patient's body size. In 2006, our group presented a nomogram that allowed interpretation of aortic size significance in relationship to a patient's body surface area (BSA). This information was most useful for very small and very large patients. It had never seemed correct that a tiny gymnast and a much larger basketball player could share the same aortic criterion for intervention. In the nomogram, BSA is plotted on one axis and the aortic size is plotted on the other axis. The intersection gives the aortic size index (ASI), which correlates closely with aortic behavior. Patients are placed into low-, medium-, and high-risk categories. Now, as our aortic patient database has grown from 230 at the time of our original publications to some 4000 today, we are able to make much more powerful statistical calculations. In this article, we demonstrate that compared with the BSA-based ASI, the height-based aortic height index (AHI) provides equal or superior prediction of aortic events, as depicted in the area under the curve analysis. This avoids the need to calculate BSA from a computer site. Note also that we use only aortic diameter, without invoking any calculation of aortic cross-sectional area. This produces a simple nomogram, permitting better categorization of patients with aortic aneurysm into low, moderate, high, or severe aortic risk categories. The tables in the present study include rupture, dissection, and death in the calculations. We are comfortable with this new method of prediction based on body size. When we used the BSA-based index, we always wondered how the aorta "knew" how heavy the patient was, and how the weight would affect the "normal" size of the aorta for that patient. Now we find that we can indeed leave the patient's weight out of consideration, with equal or better discriminatory power. We hope this nomogram is useful to clinicians in the difficult process of making the decision to proceed with prophylactic aortic surgery based on aortic diameter in asymptomatic patients. In accordance with JTCVS preference, we provide a surgical video illustrating a prophylactic operation in a patient with an ascending aortic aneurysm involving the arch and great vessels. The ascending aorta was opened. The aneurysm was then resected. The proximal anastomosis was performed with running suture, with reinforcement of the posterior wall. Deep hypothermic circulatory arrest was instituted. The aneurysmal innominate artery and the left common carotid artery were resected. The aortic arch was excised. An elephant trunk was introduced into the descending aorta, and the elephant trunk anastomosis was done with running suture with Teflon felt reinforcement. The innominate and left common carotid arteries were grafted and connected to the main graft. Video available at: http://www.jtcvsonline. org/article/S0022-5223(17)32769-1/fulltext. 
AHI, is at least as good as the ASI in predicting the risks of rupture, dissection, and death in patients with aneurysms (Video 1). The similar performance of the 2 indices is not surprising given their high correlation $(\rho=0.91)$. A technical convenience of the $\mathrm{AHI}$ is that it does not require calculation of aortic cross-sectional area needed for the index proposed by Svensson and colleagues. ${ }^{24,25}$

Based on the results of this study, an AHI of $\leq 2.43 \mathrm{~cm} / \mathrm{m}$ indicates low risk, but regular radiographic follow-up is recommended. An AHI of 2.44 to $3.17 \mathrm{~cm} / \mathrm{m}$ indicates moderate risk and warrants at least close radiographic follow-up. Patients with an AHI of 3.21 to $4.06 \mathrm{~cm} / \mathrm{m}$ are at high risk, and elective aortic repair should generally be recommended. In the subset of patients with severe risks (AHI $\geq 4.1 \mathrm{~cm} / \mathrm{m}$ ), elective surgical repair should be performed as early as possible.

In a recent study by Masri and colleagues, ${ }^{8}$ a ratio of aortic root (or ascending aortic) cross-sectional area to height was identified as an independent predictor of long-term mortality in patients with TAAA. The authors reported that this heightadjusted ascending aortic area better classified the mortality risk compared with the raw aortic diameter. However, because area is a monotone transformation of the diameter, the aortic diameter and area would be perfectly correlated, and the superior predictive value of the ratio should reside entirely in the comparison to height. In this sense, the AHI can be considered a "simpler" calculation.

\section{Limitations}

This study is limited by its retrospective nature and by potential bias in patient referral. Although our aortic size to height ratio is aimed at compensating for the risk differences skewed by stature, it should be noted that aortic size and behavior may be considerably influenced by sex. ${ }^{26-28}$ This study did not adjust for this factor, which may affect the predictive capacity of this non-sex-based, heightindexed size for adverse aortic events in different subsets of patients with aneurysms.

\section{CONCLUSIONS}

This study of the natural history of TAAA permits the following conclusions:

1. TAAAs grow slowly, at $0.14 \mathrm{~cm} /$ year.

2. The natural risk of rupture and dissection based on aortic size increases sharply at 2 hinge points: 5.25 to $5.50 \mathrm{~cm}$ and 5.75 to $6.00 \mathrm{~cm}$.

3. Indexing absolute aortic size to biometric data is a valid tool for risk estimation of rupture, dissection, or death in patients with TAAA.

4. The AHI offers another, simple alternative index for assessing the impact of a particular aortic size in a particular patient.
5. Survival calculations demonstrate powerfully the strongly negative impact of large aneurysms on longevity.

\section{Conflict of Interest Statement}

Authors have nothing to disclose with regard to commercial support.

\section{Webcast}

You can watch a Webcast of this AATS meeting presentation by going to: https://aats.blob.core.windows.net/media/ 17AM/2017-05-02/RM311/05-02-17_Room311_1555_ Zafar.mp4.

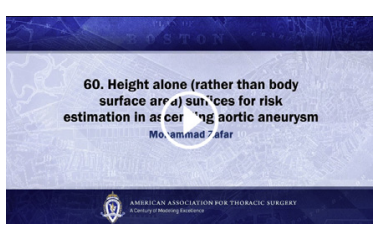

\section{References}

1. Hiratzka LF, Bakris GL, Beckman JA, Bersin RM, Carr VF, Casey DE, et al. 2010 ACCF/AHA/AATS/ACR/ASA/SCA/SCAI/SIR/STS/SVM guidelines for the diagnosis and management of patients with thoracic aortic disease: a report of the American College of Cardiology Foundation/American Heart Association Task Force on Practice Guidelines, American Association for Thoracic Surgery, American College of Radiology, American Stroke Association, Society of Cardiovascular Anesthesiologists, Society for Cardiovascular Angiography and Interventions, Society of Interventional Radiology, Society of Thoracic Surgeons, and Society for Vascular Medicine. J Am Coll Cardiol. 2010;55:e27-129.

2. Erbel R, Aboyans V, Boileau C, Bossone E, Di Bartolomeo R, Eggebrecht H, et al. 2014 ESC guidelines on the diagnosis and treatment of aortic diseases: document covering acute and chronic aortic diseases of the thoracic and abdominal aorta of the adult. The task force for the diagnosis and treatment of aortic diseases of the European Society of Cardiology (ESC). Eur Heart J. 2014;35: 2873-926.

3. Elefteriades JA, Ziganshin BA, Rizzo JA, Fang H, Tranquilli M, Paruchuri V, et al. Indications and imaging for aortic surgery: size and other matters. J Thorac Cardiovasc Surg. 2015;149(2 Suppl):S10-3.

4. Coady MA, Rizzo JA, Hammond GL, Mandapati D, Darr U, Kopf GS, et al. What is the appropriate size criterion for resection of thoracic aortic aneurysms? J Thorac Cardiovasc Surg. 1997;113:476-91; discussion 489-91.

5. Davies RR, Goldstein LJ, Coady MA, Tittle SL, Rizzo JA, Kopf GS, et al. Yearly rupture or dissection rates for thoracic aortic aneurysms: simple prediction based on size. Ann Thorac Surg. 2002;73:17-27; discussion 27-8.

6. Davis AE, Lewandowski AJ, Holloway CJ, Ntusi NA, Banerjee R, Nethononda R, et al. Observational study of regional aortic size referenced to body size: production of a cardiovascular magnetic resonance nomogram. J Cardiovasc Magn Reson. 2014;16:9.

7. Davies RR, Gallo A, Coady MA, Tellides G, Botta DM, Burke B, et al. Novel measurement of relative aortic size predicts rupture of thoracic aortic aneurysms. Ann Thorac Surg. 2006;81:169-77.

8. Masri A, Kalahasti V, Svensson LG, Roselli EE, Johnston D, Hammer D, et al. Aortic cross-sectional area/height ratio and outcomes in patients with a trileaflet aortic valve and a dilated aorta. Circulation. 2016;134: 1724-37.

9. Elefteriades JA, Farkas EA. Thoracic aortic aneurysm clinically pertinent controversies and uncertainties. J Am Coll Cardiol. 2010;55:841-57.

10. Peterss S, Charilaou P, Ziganshin BA, Elefteriades JA. Assessment of survival in retrospective studies: the Social Security Death Index is not adequate for estimation. J Thorac Cardiovasc Surg. 2017;153:899-901.

11. Dumfarth J, Chou AS, Ziganshin BA, Bhandari R, Peterss S, Tranquilli M, et al. Atypical aortic arch branching variants: a novel marker for thoracic aortic disease. J Thorac Cardiovasc Surg. 2015;149:1586-92. 
12. Du Bois D, Du Bois E. Clinical calorimetry: tenth paper: a formula to estimate the approximate surface area if height and weight be known. Arch Intern Med. 1916;XVII:863-71.

13. Rizzo JA, Coady MA, Elefteriades JA. Procedures for estimating growth rates in thoracic aortic aneurysms. J Clin Epidemiol. 1998;51:747-54.

14. Coady MA, Rizzo JA, Goldstein LJ, Elefteriades JA. Natural history, pathogenesis, and etiology of thoracic aortic aneurysms and dissections. Cardiol Clin. 1999;17:615-35. vii.

15. Viallon V, Latouche A. Discrimination measures for survival outcomes: connection between the AUC and the predictiveness curve. Biom J. 2011; 53:217-36.

16. Heagerty PJ, Lumley T, Pepe MS. Time-dependent ROC curves for censored survival data and a diagnostic marker. Biometrics. 2000;56:337-44.

17. Heagerty PJ, Zheng Y. Survival model predictive accuracy and ROC curves. Biometrics. 2005:61:92-105.

18. Coady MA, Rizzo JA, Hammond GL, Kopf GS, Elefteriades JA. Surgical intervention criteria for thoracic aortic aneurysms: a study of growth rates and complications. Ann Thorac Surg. 1999;67:1922-6; discussion 1953-8.

19. Elefteriades JA. Natural history of thoracic aortic aneurysms: indications for surgery, and surgical versus nonsurgical risks. Ann Thorac Surg. 2002;74:S1877-80; discussion S1892-8.

20. Ziganshin BA, Elefteriades JA. Guilt by association: a paradigm for detection of silent aortic disease. Ann Cardiothorac Surg. 2016;5:174-87.

21. Rylski B, Blanke P, Beyersdorf F, Desai ND, Milewski RK, Siepe M, et al. How does the ascending aorta geometry change when it dissects? J Am Coll Cardiol. 2014;63:1311-9.

22. Morales DL, Quin JA, Braxton JH, Hammond GL, Gusberg RJ, Elefteriades JA. Experimental confirmation of effectiveness of fenestration in acute aortic dissection. Ann Thorac Surg. 1998;66:1679-83.

23. Mansour AM, Peterss S, Zafar MA, Rizzo JA, Fang H, Charilaou P, et al. Prevention of aortic dissection suggests a diameter shift to a lower aortic size threshold for intervention. Cardiology. January 19, 2018 [Epub ahead of print].

24. Svensson LG, Khitin L. Aortic cross-sectional area/height ratio timing of aortic surgery in asymptomatic patients with Marfan syndrome. J Thorac Cardiovasc Surg. 2002;123:360-1

25. Svensson LG, Kim KH, Lytle BW, Cosgrove DM. Relationship of aortic crosssectional area to height ratio and the risk of aortic dissection in patients with bicuspid aortic valves. J Thorac Cardiovasc Surg. 2003;126:892-3.

26. Cheung K, Boodhwani M, Chan KL, Beauchesne L, Dick A, Coutinho T. Thoracic aortic aneurysm growth: role of sex and aneurysm etiology. J Am Heart Assoc. 2017;6:e003792.

27. Sokolis DP, Iliopoulos DC. Impaired mechanics and matrix metalloproteinases/ inhibitors expression in female ascending thoracic aortic aneurysms. $J \mathrm{Mech} \mathrm{Be}$ hav Biomed Mater. 2014;34:154-64.

28. Makrygiannis G, Courtois A, Drion P, Defraigne JO, Kuivaniemi H, Sakalihasan N. Sex differences in abdominal aortic aneurysm: the role of sex hormones. Ann Vasc Surg. 2014;28:1946-58.

Key Words: thoracic aortic aneurysm, ascending aorta, natural history, risk estimation, aortic rupture, dissection, death, aortic height index

\section{Discussion}

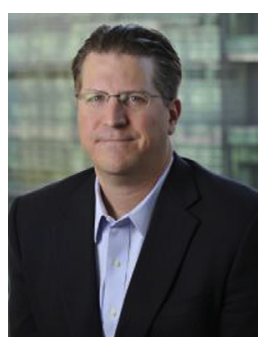

Dr T. Reece (Denver, Colo). I would like to thank the AATS for the opportunity to discuss this paper and for the manuscript well in advance. It was very well presented, and the manuscript is very well done. You study a simplified method for evaluating the relative aortic size in patients, particularly without defining the BSA. I have a few questions.

First of all, how can we use this to utilize an ability to say that patients are not going to need anything in the future? So when we get a $3.5-\mathrm{cm}$ aneurysm in the clinic, can we say there is no risk of this patient moving forward, we don't need to do any follow-up, or do we still need to continue to follow-up these patients?

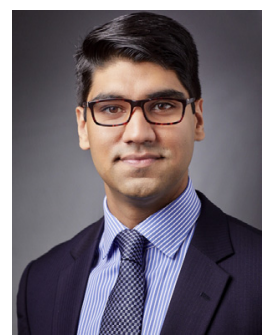

Dr Mohammad A. Zafar (New Haven, Conn). Thank you very much for your question, sir. We haven't studied the smallest aneurysm group in great detail, but we don't call back patients for follow-up into clinic unless the aorta is greater than or equal to $3.8 \mathrm{~cm}$. Having said that, we don't usually see patients with such small aortas in the $3.5-\mathrm{cm}$ size range unless something is going on, for example, if they have a family history of dissection, a connective tissue disorder, or symptoms, for that matter.

Dr Reece. In my clinic, all that has to be said is they have a big aorta on their radiology report and they get to come see me, so that's why that question is there.

The risk subsets are defined as a percent risk of any of the complications per year, at $4 \%, 7 \%, 12 \%$, and $18 \%$. How do you define those set points, and how can we justify either operating or not operating on somebody that has a $7 \%$ risk of having a problem per year? And your suggestion on those patients is that we should follow them up "closely." So what does that mean, "closely," and why can't we do a low risk hemiarch on those patients if the risk of them having a complication of their aorta is $7 \%$ ?

Dr Zafar. Thank you for your question, sir. We wholeheartedly agree with you about the safety of aortic surgery in the present era. In addition to what you have said, alluding to the safety of aortic surgery, there are also several other points that lend credence to a slight "leftward shift" in the criteria for intervention: In a recent study by our institution, we discovered that aortic size increases by approximately $7 \mathrm{~mm}$ instantaneously at the time of dissection. Therefore, on an immediate postdissection computed tomography (CT) scan, the size of the aorta may actually be overestimated, and the size at dissection is in fact smaller.

Another point regarding the leftward shift in the intervention criteria is that our investigations have found that the new centerline CT method used by radiologists to image aortas and report aortic size actually underestimates aortic size by about $5 \mathrm{~mm}$ or so. Furthermore, as displayed on the hinge point graph that we showed, we have been able to zero in on the $5-6 \mathrm{~cm}$ aortic size range because of the increased patient numbers that we have at our disposal for analysis, and we found that there is an earlier hinge point at a diameter of $5.25 \mathrm{~cm}$, where the risk increases.

Therefore, we agree that a slight left shift in intervention criteria should be considered.

Dr Reece. And my last question is that we are using most of the indexing or whatever we are going to call relative 
sizing of this in the smaller patients. Do you feel like your numbers of patients in these ranges are large enough for us to actually use these criteria for us to intervene on Turner's patients, et cetera, or smaller patients with relatively small aortas?

Dr Zafar. Based on aortic size and the patient's height, if the patient is in a significantly high-risk category, then we feel that intervention is warranted. However, with respect to the extremes of sizes, height follows a bell-curve distribution, and therefore, at the tail end of the bell curve, there are very few patients. But, yes, if they do fall into high-risk categories, we do recommend surgical intervention.

Dr Reece. I just worry when we apply the R2 to a whole list of sizes about patients and aortas that we are losing focus on the smaller patients with smaller aortas that we need to intervene upon and how we can validate that.

Dr Zafar. We agree with this concern.

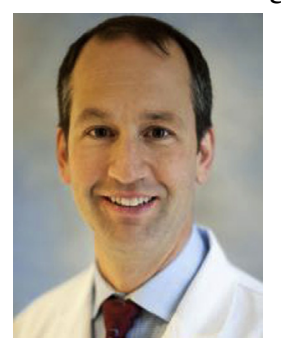

Dr M. Borger (Leipzig, Germany). Once you have published your data and corresponding nomograms, there are going to be some people that are going to operate on a $160-\mathrm{cm}$ person with a 4.9-cm aneurysm, and I'm still confused as to why that should be done. We know that the risk of dissection and rupture are directly related to wall tension. According to Laplace's law, wall tension has nothing to do with the size of the container on the outside of the tube that's containing the pressurized fluid. So why does the aorta care how big the body is outside of the aorta?

Dr Zafar. Thank you very much for your question, sir. In our opinion, a confluence of factors may influence the risk of aortic rupture and dissection. Since aortic size is likely genetically predetermined, and height is also genetically predetermined, a taller individual would most likely have a larger aorta (which would be normal for that patient size) than a shorter individual. Thus, we believe that the risk of rupture and dissection can be effectively predicted based on the patient's height.

Dr Borger. So you are saying there are other things than wall tension that are determining the risk of rupture or dissection. That is the only logical explanation, right?

Dr Zafar. Yes, sir. If you are alluding to smaller sized aortas rupturing and dissecting, a large portion of the population has aortas in that smaller size range. So, although dissections are occurring at smaller sizes, the denominator, that is, the patients at risk in that size range, is quite large as well.

Dr Borger. The aorta size paradox, yes. I am still waiting for a good answer to that question, and if somebody knows the answer to it, please tell me what it is.

Unidentified Speaker. Does anyone know if aortic wall thickness varies with height?

Dr Borger. That could certainly be the answer, but nobody has demonstrated it yet.

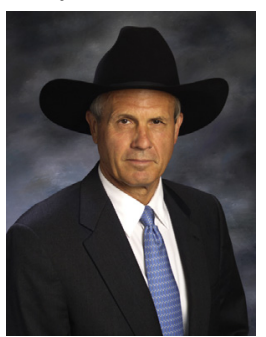

Dr C. Miller (Stanford, Calif). Nice presentation. I know you have the blessing of great statistical resources at Yale, but I'm troubled by a linear $R^{2}$ correlation for goodness of fit comparing your 2 curves; seems overly simplistic. Furthermore, both $R^{2}$ values were in the noise level, which means the comparison does not convey any meaningful or useful information. Why didn't you do a proper sensitivity analysis with an AUC?

Dr Zafar. Thank you very much for your question, sir. The statistical analyses were done by a dedicated statistical team; Drs Rizzo and Li are statistical experts and have worked with us on this project from the beginning. Thank you very much for your valuable suggestion; we will certainly take it into account and will include the sensitivity analysis with an AUC in the revised manuscript. 